\title{
Total Semi - $\mu$ Strong (Weak) Domination in Intuitionistic Fuzzy Graph
}

\author{
P.J. Jayalakshmi ${ }^{1}$ and Dr.C.V.R. Harinarayanan ${ }^{2}$ and Dr. P. Muthuraj \\ ${ }^{1}$ Associate Professor, Indra Ganesan College of Engineering, Trichy - 620 012, Tamilnadu, India. \\ ${ }^{2}$ Assistant Professor, Government Arts College, Paramakudi, Tamilnadu, India. \\ ${ }^{3}$ Assistant Professor, H.H. The Raja's College, Pudukottai, Tamilnadu, India
}

\begin{abstract}
In the initial stage we proposed the concept of Total Strong (Weak) domination in Fuzzy graph. It deal with the real time application that helps a individual person in crossing a road traffic signal. We will be giving a single value for vertices and edges. Enhancing the same concept, the Total Strong (Weak) domination in Intuitionistic Fuzzy graph was proposed. Here we will be giving a double value for the vertices and edges. Now in this paper, we demonstrate the concept of Total Semi- $\mu$ Strong (Weak) domination in Intuitionistic Fuzzy Graph. Theoretically Semi- $\mu$ Strong intuitionistic fuzzy graphs took minimum value between the two edges. Also we have proved some equivalent theorems and examples.

Index Terms: Intuitionistic Fuzzy graph, Strong (Weak) intuitionistic fuzzy graph, Total Strong (Weak) IFG, Total Semi - $\mu$ Strong (Weak) Domination in IFG, Fuzzy domination number. MSC2016 codes - 05C72, 05C69, 03E72, 03F55
\end{abstract}

\section{Introduction}

Initially the definition of Fuzzy graph was given by Katmann from the fuzzy relations introduced by Zadeh[1]. Rosenfield proposed another detailed definitions, including fuzzy vertex and fuzzy edges, and several fuzzy analogues of graph theoretic graph was investigated by A. Somasundaram[3], S. Somasundaram. Also A. Somasundaram present the concept of independent domination of fuzzy graphs. C. Natarajan [4] and S.K.Ayyasamy proposed the strong (weak) domination in fuzzy graph. P.J. Jayalakshmi [5] and C.V.R. Harinarayanan introduce the Total strong (weak) domination in Fuzzy graphs. M.G. Karunambigai [2], R.Parvathi and R. Bhuvaneswari proposed constant intuitionistic Fuzzy graph; and totally constant IFG.

P.Parvathi and R. Bhuvaneswari proposed constant intuitionistic Fuzzy graph; and totally constant IFG. [2] R. Parvathi and G. Thamizhendhi fuzzy graph; A new approach was investigated S. Ismail Mohideen and A. Mohamed Ismail. [9] In this paper, we develop a total strong (weak) dominating intuitionistic Fuzzy graphs.

Definition 2.1: (IFG)

\section{Basic Definitions}

An intuitionistic fuzzy graph (IFG) is of the form $G=(V, E)$, where $V=\left\{v_{1} v_{2} \ldots v_{n}\right\}$ such that (i) $\mu_{1}: \mathrm{V} \rightarrow[0,1], \gamma_{1}: \mathrm{V} \rightarrow[0,1]$ denote the degree of membership and non-membership of the element $\mathrm{v}_{\mathrm{i}} \in \mathrm{V}$ respectively and $0 \leq \mu_{1}\left(\mathrm{v}_{\mathrm{i}}\right)+\gamma_{1}\left(\mathrm{~V}_{\mathrm{i}}\right) \leq 1$ for every $\mathrm{v}_{\mathrm{i}} \in \mathrm{V},(\mathrm{i}=1,2, \ldots \mathrm{n})$

(ii) $\mathrm{E} \subseteq \mathrm{V} \times \mathrm{V}$ where $\mu_{2}: \mathrm{V} \times \mathrm{V} \rightarrow[0,1]$ and $\gamma_{2}: \mathrm{V} \times \mathrm{V} \rightarrow[0,1]$ are such that $\mu_{2}\left(\mathrm{~V}_{\mathrm{i}} \mathrm{V}_{\mathrm{j}}\right) \leq \mu_{1}\left(\mathrm{~V}_{\mathrm{i}}\right) \wedge \mu_{1}\left(\mathrm{~V}_{\mathrm{j}}\right), \gamma_{2}\left(\mathrm{~V}_{\mathrm{i}}\right.$, $\left.\mathrm{V}_{\mathrm{j}}\right) \leq \gamma_{1}\left(\mathrm{~V}_{\mathrm{i}}\right) \wedge \gamma_{1}\left(\mathrm{~V}_{\mathrm{j}}\right)$ and $0 \leq \mu_{2}\left(\mathrm{~V}_{\mathrm{i}} \mathrm{V}_{\mathrm{j}}\right)+\gamma_{2}\left(\mathrm{~V}_{\mathrm{i}}, \mathrm{V}_{\mathrm{j}}\right) \leq 1$

Definition 2.2: (Strong arc)

An arc $(\mathrm{Vi}, \mathrm{Vj})$ of an IFG G is called an strong arc if $\mu_{2}\left(\mathrm{~V}_{\mathrm{i}} \mathrm{V}_{\mathrm{j}}\right) \leq \mu_{1}\left(\mathrm{~V}_{\mathrm{i}}\right) \wedge \mu_{1}\left(\mathrm{~V}_{\mathrm{j}}\right)$ and $\gamma_{2}\left(\mathrm{~V}_{\mathrm{i}}, \mathrm{V}_{\mathrm{j}}\right) \leq \gamma_{1}\left(\mathrm{~V}_{\mathrm{i}}\right) \wedge \gamma_{1}\left(\mathrm{~V}_{\mathrm{j}}\right)$

Definition 2.3: (Cardinality)

Let $\mathrm{G}=(\mathrm{V}, \mathrm{E})$ be a IFG. Then the cardinality of $\mathrm{G}$ is defined to be

$$
|G|=\left|\sum_{V_{i} \in \mathrm{V}}\left[\frac{1+\mu_{1}\left(v_{i}\right)-\gamma_{1}\left(v_{i}\right)}{2}\right]+\sum_{V_{i} \in \mathrm{V}}\left[\frac{1+\mu_{2}\left(v_{i} v_{j}\right)-\gamma_{2}\left(v_{i} v_{j}\right)}{2}\right]\right|
$$


Definition 2.4: (Vertex cardinality)

The vertex cardinality of $G$ is defined by

$$
|\mathrm{V}|=\sum_{V_{i} \in \mathrm{V}}\left[\frac{1+\mu_{1}\left(v_{i}\right)-\gamma_{1}\left(v_{i}\right)}{2}\right]
$$

Definition 2.5: (Edge Cardinality)

The edge cardinality of $\mathrm{G}$ is defined by

$$
|\mathrm{E}|=\sum_{V_{i} \in \mathrm{V}}\left[\frac{1+\mu_{2}\left(v_{i} v_{j}\right)-\gamma_{2}\left(v_{i} v_{j}\right.}{2}\right]
$$

The vertex cardinality of an IFG is called the order of $\mathrm{G}$ and it is denoted by $\mathrm{O}(\mathrm{G})$. The cardinality of the edges in $\mathrm{G}$ is called the size of $\mathrm{G}$. It is denoted by $\mathrm{S}(\mathrm{G})$.

\section{Definition 2.6: (Complement of an Intuitionistic Fuzzy graph)}

The Complement of an Intuitionistic Fuzzy graph, $\mathrm{g}=(\mathrm{V}, \mathrm{E})$ is an IFG, $\bar{G}=(\overline{\bar{V}}, \bar{E})$, where

(i) $\bar{V}=\mathrm{v}$

(ii) $\bar{\mu}_{1 \mathrm{i}}=\mu_{1 \mathrm{i}}$ and $\bar{\gamma}_{1 \mathrm{i}}=\gamma_{1 \mathrm{i}}$ for all $\mathrm{I}=1,2, \ldots \mathrm{n}$

(iii) $\bar{\mu}_{2 \mathrm{ij}}=\min \left(\mu_{1 \mathrm{i}}, \mu_{1 \mathrm{j}}\right)-\mu_{2 \mathrm{ij}}$ and $\bar{\gamma}_{2 \mathrm{ij}}=\max \left(\gamma_{1 \mathrm{i}}, \gamma_{1 \mathrm{j}}\right)-\gamma_{2 \mathrm{ij}}$ for all $\mathrm{I}, \mathrm{j}=1,2, \ldots \mathrm{n}$

\section{Definition 2.7: $\left(\operatorname{Min}^{\mathrm{m}} \& M^{\mathrm{ma}}{ }^{\mathrm{m}}\right.$ degree of $\left.\mathrm{G}\right)$}

The effective degree of a vertex $\mathrm{V}$ in IFG, $\mathrm{G}=(\mathrm{V}, \mathrm{G})$ is defined to be sum of the strong edges incident at $\mathrm{V}$. It is denoted by $\delta_{\mathrm{E}}(\mathrm{V})$. The $\min ^{\mathrm{m}}$ degree of $\mathrm{G}$ is $\delta_{-} \mathrm{E}(\mathrm{G})=\min \left\{\mathrm{d}_{\mathrm{E}}(\mathrm{V}) / \mathrm{v} \in \mathrm{V}\right\}$.

The $\max ^{\mathrm{m}}$ degree of $\mathrm{G}$ is $\Delta_{\mathrm{E}}(\mathrm{G})=\max \left\{\mathrm{d}_{\mathrm{E}}(\mathrm{V}) / \mathrm{v} \in \mathrm{V}\right\}$. Two vertices $\mathrm{v}_{\mathrm{i}}$ and $\mathrm{v}_{\mathrm{j}}$ are said to be neighborhood in IFG there is a strong arc between $v_{i}$ and $v_{j}$.

\section{Definition 2.8: (Intuitionistic Fuzzy sub graph)}

An IFG $H^{\prime}=\left(V^{\prime}, \mathrm{E}\right)$ is said to be an Intuitionistic fuzzy sub graph og $\mathrm{G}=(\mathrm{V}, \mathrm{E})$ if $v^{\prime} \subseteq \mathrm{v}$ and $E^{\prime} \subseteq \mathrm{E}$. That is $\mu_{1 \mathrm{i}}^{\prime} \leq \mu_{1 \mathrm{i}} ; \gamma^{\prime}{ }_{1 \mathrm{i}} \geq \gamma_{1 \mathrm{i}}$ and $\mu^{\prime}{ }_{2 \mathrm{ij}} \leq \mu_{2 \mathrm{ij}} ; \gamma^{\prime}{ }_{2 \mathrm{ij}} \leq \gamma_{2 \mathrm{ij}}$ for every $\mathrm{i}, \mathrm{j}=1,2, . . \mathrm{n}$.

\section{Definition 2.9 (Path)} satisfied.

A path in an IFG is a sequence of distinct vertices $v_{1}, v_{2}, \ldots v_{n}$ such that either one of the following is

(i) $\mu_{2}\left(v_{i}, v_{j}\right)>0, \gamma_{2}\left(v_{i}, v_{j}\right)>0$ for some i \& j

(ii) $\mu_{2}\left(v_{\mathrm{i}}, \mathrm{v}_{\mathrm{j}}\right)=0, \gamma_{2}\left(\mathrm{v}_{\mathrm{i}}, \mathrm{v}_{\mathrm{j}}\right)>0$ for some i \& j

(iii) $\mu_{2}\left(v_{\mathrm{i}}, \mathrm{v}_{\mathrm{j}}\right)>0, \gamma_{2}\left(\mathrm{v}_{\mathrm{i}}, \mathrm{v}_{\mathrm{j}}\right)=0$ for some $\mathrm{i} \& \mathrm{j}$

\section{Definition 2.10 (Intuitionistic Fuzzy graph)}

Let $\mathrm{G}=(\mathrm{V}, \mathrm{E})$ be an IFG. Let $\mathrm{u}, \mathrm{v} \in \mathrm{V}$, we say that $\mathrm{u}$ dominates $\mathrm{v}$ in $\mathrm{G}$ if there exists a strong arc between them. A subset $\mathrm{D} \subseteq \mathrm{V}$ is said to be dominating set in $\mathrm{G}$ if for every $\mathrm{v} \in \mathrm{V}-\mathrm{D}$, there exists u dominates v.

\section{Definition 2.11 (Intuitionistic fuzzy domination number)}

A dominating set D of IFG is said to be minimal dominating set if no proper subset of $\mathrm{S}$ is a dominating set. Minimum cardinality among all minimal dominating set is called the Intuitionistic fuzzy domination number, and is denoted by $\gamma_{\mathrm{if}}(\mathrm{G})$ 


\section{Main Definitions}

Definition 3.1: (Strong(Weak) Intuitionistic Fuzzy Domination Number)

Let $u$ and $v$ be any two vertices of an IFG of G. The $u$ strongly dominates $v$ (v weakly dominates $u$ ) if

(i) Strong arc between $u$ and $v$

(ii) $\mathrm{d}_{\mathrm{N}}(\mathrm{u}) \geq \mathrm{d}_{\mathrm{N}}(\mathrm{v})$

A strong (weak) dominating set $\mathrm{S}$ of an IFG is said to be minimal strong (weak) dominating set if no proper subset of $\mathrm{S}$ is strong (weak) dominating set of $\mathrm{G}$. The minimum cardinality among all minimal strong (weak) dominating set is called strong (weak) intuitionistic fuzzy domination number of G, and is denoted by $\gamma_{\text {sif }}(G)\left(\gamma_{\text {wif }}(G)\right.$.

\section{Definition 3.2 (Total domination)}

The set $S$ is said to be total dominating set if for every vertex $v \in \gamma(\mathrm{G}), \mathrm{V}$ is adjacent to atleast one vertex of $S$.

\section{Definition 3.3:( Strong Intuitionistic Fuzzy graph)}

An IFG, $G=\left\langle\mathrm{V}\right.$, E $>$ is said to be strong IFG if $\mu_{2 \mathrm{ij}}=\min \left(\mu_{1 \mathrm{i}}, \mu_{1 \mathrm{j}}\right)$ and $\gamma_{2 \mathrm{ij}}=\max \left(\gamma_{1 \mathrm{i}}, \gamma_{1 \mathrm{j}}\right)$ for all $\mathrm{v}_{\mathrm{i}}, \mathrm{v}_{\mathrm{j}} \in \mathrm{E}$

\section{Definition 3.4 ( Total Strong (Weak) Fuzzy vertex domination)}

Let $\mathrm{u}$ and $\mathrm{v}$ be any two vertices of a fuzzy graph $\mathrm{G}$. Then u strongly dominates $\mathrm{v}(\mathrm{v}$ weakly dominates u) if (i) $\mu(\mathrm{u}, \mathrm{v})=\sigma(\mathrm{u}) \wedge \sigma(\mathrm{v})$ and (ii) $\mathrm{d}_{\mathrm{N}}(\mathrm{u}) \geq \mathrm{d}_{\mathrm{N}}(\mathrm{v})$ (iii) for every vertex $\mathrm{v} \in \gamma(\mathrm{G})$; $\mathrm{v}$ is adjacent to at least one vertex of $\mathrm{S}$.

Definition 3.5: (Total Strong (Weak) domination in intuitionistic Fuzzy graph)

(i) An IFG is of the form $G=(V, E)$ where $V=\left\{v_{1} v_{2} v_{3} \ldots v_{n}\right\}$ such that $\mu_{1}: V \rightarrow[0,1], \gamma_{1}: V \rightarrow[0,1]$ denotes the degree of membership and non-membership of the element $v_{i} \in V$ replay and $0 \leq \mu_{1}\left(v_{1}\right)+\gamma_{1}\left(v_{1}\right) \leq 1$, for every $v_{\mathrm{i}} \in \mathrm{V}$

(ii) $\mathrm{E} \subseteq \mathrm{V} x \mathrm{~V}$ where $\mu_{2}: \mathrm{V} x \mathrm{~V} \rightarrow[0,1]$ and $\mu_{2}\left(\mathrm{v}_{\mathrm{i}}, \mathrm{v}_{\mathrm{j}}\right) \leq \min \left(\mu_{1}\left(\mathrm{v}_{\mathrm{i}}\right), \mu_{1}\left(\mathrm{v}_{\mathrm{j}}\right)\right) \gamma_{2}\left(\mathrm{v}_{\mathrm{i}}, \mathrm{v}_{\mathrm{j}}\right) \leq \max \left(\gamma_{1}\left(\mathrm{v}_{\mathrm{i}}, \gamma_{1}\left(\mathrm{v}_{\mathrm{j}}\right)\right)\right.$ and 0 $\leq \mu_{2}\left(v_{i}, v_{j}\right)+\gamma_{2}\left(v_{i}, v_{j}\right) \leq 1$ for every $\left(v_{i}, v_{j}\right) \in E$.

(iii) $\mu(\mathrm{u}, \mathrm{v})=\sigma(\mathrm{u}) \wedge \sigma(\mathrm{v})$

(iv) $d_{N}(u) \geq d_{N}(v)$ and (v) for every vertex $v \in V(G)$; $V$ is adjacent to atleast one vertex of $S$

\section{Definition 3.6: (Regular Intuitionistic Fuzzy Graph)}

An IFG G $=\langle\mathrm{V}, \mathrm{E}\rangle$ is said to be regular IFG, if there is a vertex which is adjacent to vertices with same degree.

\section{Definition 3.7: (Degree of vertex in Intuitionistic Fuzzy Graph)}

Let $\mathrm{G}=\langle\mathrm{V}, \mathrm{E}>$ be an IFG. Then the degree of a vertex $\mathrm{V}$ is defined by $\mathrm{d}(\mathrm{v})=\mathrm{d}\left(\mathrm{d}_{\mu}(\mathrm{v}), \mathrm{d}_{\gamma}(\mathrm{v})\right)$ where

and

$$
\mathrm{d}_{\mu}(\mathrm{v})=\sum_{\mathrm{u} \neq v} \mu_{2}(\mathrm{u}, \mathrm{v})
$$

$$
\mathrm{d}_{\gamma}(\mathrm{v})=\sum_{\mathrm{u} \neq v} \gamma_{2}(\mathrm{u}, \mathrm{v})
$$

Definition 3.8: ( Order of Intuitionistic Fuzzy Graph)

Let $\mathrm{G}=\langle\mathrm{V}, \mathrm{E}\rangle$ be an IFG. Then the order of $\mathrm{G}$ is defined to be $\mathrm{O}(\mathrm{G})=\left(\mathrm{O}_{\mu}(\mathrm{G}), \mathrm{O}_{\gamma}(\mathrm{G})\right)$

$$
\mathrm{O}_{\mu}(\mathrm{G})=\sum_{\mathrm{u} \in V} \mu(\mathrm{v})
$$


and

$$
\mathrm{O}_{\gamma}(\mathrm{G})=\sum_{\mathrm{u} \in V} \gamma_{1}(\mathrm{v})
$$

Definition 3.9 (Size of IFG)

Let $\mathrm{G}=\langle\mathrm{V}, \mathrm{E}\rangle$ be an IFG, then the size of $\mathrm{G}$ is defined to be $\mathrm{S}(\mathrm{G})=\left(\mathrm{S}_{\mu}(\mathrm{G}), \mathrm{S}_{\gamma}(\mathrm{G})\right.$

Where

$$
\mathrm{S}_{\mu}(\mathrm{G})=\sum_{\mathrm{u} \neq v} \mu_{2}(\mathrm{u}, \mathrm{v})
$$

and

$$
\mathrm{S}_{\gamma}(\mathrm{G})=\sum_{\mathrm{u} \neq v} \gamma_{2}(\mathrm{u}, \mathrm{v})
$$

Definition 3.10: (Semi- $\mu$ Strong Intuitionistic Fuzzy Graph)

An IFG, $G=\left\langle\right.$ V, E $>$ is said to be a semi $-\mu$ Strong and $\mu_{2 \mathrm{ij}}=\min \left(\mu_{1 \mathrm{i}}, \mu_{1 \mathrm{j}}\right)$ for every $\quad \mathrm{i}$ and $\mathrm{j}$.

Definition 3.11 (Total semi - $\mu$ strong(weak) domination in IFG ( ts $_{\mu^{-}}$sifg))

(i) An IFG is of the form $\mathrm{G}=(\mathrm{V}, \mathrm{E})$ where $\mathrm{V}=\left\{\mathrm{v}_{1}, \mathrm{v}_{2}, \ldots \mathrm{v}_{\mathrm{n}}\right\}$ such that

$\mu_{1}: \mathrm{V} \rightarrow[0,1], \gamma_{1}: \mathrm{V} \rightarrow[0,1]$ denotes the degree of membership and non - membership of the element $v_{\mathrm{i}} \in \mathrm{V}$ respectively and $0 \leq \mu_{1}\left(\mathrm{v}_{1}\right)+\gamma_{1}\left(\mathrm{v}_{1}\right) \leq 1$ for every $\mathrm{v}_{\mathrm{i}} \in \mathrm{V}$

(ii) $\mathrm{E} \subseteq \mathrm{V} \times \mathrm{V}$ where $\mu_{2}: \mathrm{V} \times \mathrm{V} \rightarrow[0,1]$ and $\gamma_{2}: \mathrm{V} \times \mathrm{V} \rightarrow[0,1]$ are such that $\mu_{2}\left(V_{i} V_{j}\right) \leq \min \left(\mu_{1}\left(V_{i}\right) \mu_{1}\left(V_{j}\right)\right)$

$\gamma_{2}\left(\mathrm{~V}_{\mathrm{i}}, \mathrm{V}_{\mathrm{j}}\right) \leq \max \left(\gamma_{1}\left(\mathrm{~V}_{\mathrm{i}}\right) \wedge \gamma_{1}\left(\mathrm{~V}_{\mathrm{j}}\right)\right)$ and $0 \leq \mu_{2}\left(\mathrm{~V}_{\mathrm{i}} \mathrm{V}_{\mathrm{j}}\right)+\gamma_{2}\left(\mathrm{~V}_{\mathrm{i}}, \mathrm{V}_{\mathrm{j}}\right) \leq 1$ for every $(\mathrm{vi}, \mathrm{vj}) \in \mathrm{E}$

(iii) Semi $-\mu$ strong if $\mu_{2 \mathrm{ij}}=\min \left(\mu_{1 \mathrm{i}}, \mu_{1 \mathrm{j}}\right)$

(iv) $\mu(\mathrm{u}, \mathrm{v}) \geq \sigma(\mathrm{u}) \wedge \sigma(\mathrm{v})$

(v) $\mathrm{d}_{\mathrm{N}}(\mathrm{u}) \geq \mathrm{d}_{\mathrm{N}}(\mathrm{v})$ and

(vi) For every vertex $v \in V(G)$; $V$ is adjacent to atleast one vertex of $S$

\section{Theorem 4.1:}

\section{Theoretical Results}

Let $\mathrm{D}$ be a minimal $\mathrm{ts}_{\mu}$-sifd - set of an Semi- $\mu$ intuitionistic fuzzy graph $\mathrm{G}$. Then for each $V \in \mathrm{D}$ if and only if one of the following holds

(i) No vertex in $\mathrm{D}$ strongly dominates $\mathrm{V}$.

(ii) There exists $u \in V$ - D such that $V$ is the only vertex in $\mathrm{D}$ which strongly dominates $\mathrm{u}$.

Proof:

Assume Part:

Assume that $\mathrm{D}$ is a minimal $\mathrm{ts}_{\mu}-$ sifd - set of $\mathrm{G}$. Then for every vertex $\mathrm{V} \in \mathrm{D}, \mathrm{D}-\mathrm{u}$ is not a total semi $\mu$ strong dominating set and hence there exists $u \in V-(D-\{u\})$, which is not strongly dominated by any vertex in $\mathrm{D}-\{\mathrm{V}\}$. If $\mathrm{u}=\mathrm{v}$, we get $\mathrm{u}$ is not strongly dominated by vertex in $\mathrm{D}$. If $\mathrm{u} \neq \mathrm{v}, \mathrm{u}$ is strongly dominated by $\mathrm{D}-$ $\{\mathrm{u}\}$, but $\mathrm{u}$ is strongly dominated by $\mathrm{D}$, then the vertex $\mathrm{u}$ is strongly dominated by a vertex $\mathrm{v}$ in $\mathrm{D}$.

\section{Converse Part:}

Conversely assume that $\mathrm{D}$ is a total strong dominating set and for each vertex $\mathrm{V} \in \mathrm{D}$, one of the two conditions holds

(a) Suppose $\mathrm{D}$ is not minimal total semi- $\mu$ strong dominating set, then there exists a vertex $V \in D, D-\{v\}$ is a total semi- $\mu$ strong dominating set. Hence $\mathrm{V}$ is strongly dominated by atleast one vertex in $\mathrm{D}-\{\mathrm{v}\}$, the condition one does not hold. 
(b) If $\mathrm{D}-\{\mathrm{v}\}$ is a total semi- $\mu$ strong dominating set then every vertex in $\mathrm{V}-\mathrm{D}$ is a strongly dominated by atleast one vertex in D- $\{\mathrm{v}\}$, the second condition does not hold.

Which is contradiction that atleast one of these condition holds. So D is a minimal total semi- $\mu$ strong dominating set.

\section{Theorem 4.2:}

Let $\mathrm{D}$ be a minimal total semi- $\mu$ strong intuitionistic fuzzy dominating set of an IFG. Then for each $\mathrm{V}$ $\in \mathrm{D}$ iff the following holds.

(i) No vertex in $\mathrm{D}$ weakly dominates $\mathrm{V}$

(ii) There exists $u \in V$ - D such that $V$ is the only vertex in $\mathrm{D}$ which weakly dominates $\mathrm{u}$.

\section{Preposition 4.3:}

For an semi- $\mu$ intuitionistic fuzzy graph $\mathrm{G}$, of order $\mathrm{O}(\mathrm{G})$

(i) $\gamma_{\text {tsif }}(\mathrm{G}) \leq \mathrm{t}_{\mathrm{ts} \mu \text { sif }} \leq \mathrm{O}(\mathrm{G})-\Delta_{\mathrm{N}}(\mathrm{G}) \leq \mathrm{O}(\mathrm{G})-\Delta_{\mathrm{E}}(\mathrm{G})$

(ii) $\gamma_{\text {tsif }}(\mathrm{G}) \leq \mathrm{t}_{\mathrm{ts} \mu \text { wif }} \leq \mathrm{O}(\mathrm{G})-\delta_{\mathrm{N}}(\mathrm{G}) \leq \mathrm{O}(\mathrm{G})-\delta_{\mathrm{E}}(\mathrm{G})$

\section{Proof:}

Since every $\mathrm{ts}_{\mu^{-}}$sifd - set $\left(\mathrm{ts}_{\mu}\right.$-wifd set) is intuitionistic fuzzy dominating set of semi- $\mu \mathrm{G}$,

$$
\begin{aligned}
& \gamma_{\text {tsif }}(\mathrm{G}) \leq \gamma_{\text {tsusif }}(\mathrm{G}) \text { and } \\
& \gamma_{\text {twif }}(\mathrm{G}) \leq \gamma_{\text {ts } \mu \text { wif }}(\mathrm{G})
\end{aligned}
$$

Let $\mathrm{u}, \mathrm{v} \in \mathrm{V}$, if $\mathrm{d}_{\mathrm{N}}(\mathrm{u})=\Delta_{\mathrm{N}}(\mathrm{G})$ and

$$
\mathrm{d}_{\mathrm{N}}(\mathrm{v})=\delta_{\mathrm{N}}(\mathrm{G})
$$

Then $\mathrm{V}-\mathrm{N}(\mathrm{u})$ is a ts ${ }_{\mu}$ - sifd - set but not minimal and $\mathrm{V}-\mathrm{N}(\mathrm{v})$ is a $\mathrm{ts}_{\mu}$ - wifd - set but not minimal. Therefore $\gamma_{\mathrm{ts} \mu \text {-sif }}(\mathrm{G}) \leq|\mathrm{V}|-|\mathrm{N}(\mathrm{u})|_{\mathrm{tsif}}$

$$
\begin{aligned}
\text { (i.e) } \mid \mathrm{V}- & \left.\mathrm{N}(\mathrm{u})\right|_{\mathrm{tsif}}=|\mathrm{V}|-|\mathrm{N}(\mathrm{u})| \\
& \Longrightarrow \mathrm{O}(\mathrm{G})-\mathrm{d}_{\mathrm{N}}(\mathrm{u}) \\
& \Rightarrow \mathrm{O}(\mathrm{G})-\Delta_{\mathrm{N}}(\mathrm{G}) \\
& \Rightarrow \gamma_{\mathrm{ts} \mu \text {-sif }}(\mathrm{G}) \leq \mathrm{O}(\mathrm{G})-\Delta 0_{\mathrm{N}}(\mathrm{G}) \text { and } \\
& \gamma_{\mathrm{ts} \mu \text {-wif }}(\mathrm{G}) \leq|\mathrm{V}-\mathrm{N}(\mathrm{u})|_{\mathrm{twif}} \\
& \Rightarrow \mathrm{O}(\mathrm{G})-\mathrm{d}_{\mathrm{N}}(\mathrm{v}) \\
& \Rightarrow \mathrm{O}(\mathrm{G})-\delta_{\mathrm{N}}(\mathrm{G}) \\
& \Rightarrow \gamma_{\mathrm{ts} \mu \text {-wif }}(\mathrm{G}) \leq \mathrm{O}(\mathrm{G})-\delta_{\mathrm{N}}(\mathrm{G})
\end{aligned}
$$

Further since $\Delta_{\mathrm{E}}(\mathrm{G}) \leq \Delta_{\mathrm{N}}(\mathrm{G})$ and $\delta_{\mathrm{E}}(\mathrm{G}) \leq \delta_{\mathrm{N}}(\mathrm{G})$

$$
\begin{aligned}
& \Rightarrow \gamma_{\text {tsif }}(\mathrm{G}) \leq \mathrm{t}_{\mathrm{ts} \text { sif }}(\mathrm{G}) \leq \mathrm{O}(\mathrm{G})-\Delta_{\mathrm{N}}(\mathrm{G}) \leq \mathrm{O}(\mathrm{G})-\Delta_{\mathrm{E}}(\mathrm{G}) \\
& \Rightarrow \gamma_{\text {twif }}(\mathrm{G}) \leq \mathrm{t}_{\text {tsuwif }}(\mathrm{G}) \leq \mathrm{O}(\mathrm{G})-\delta_{\mathrm{N}}(\mathrm{G}) \leq \mathrm{O}(\mathrm{G})-\delta_{\mathrm{E}}(\mathrm{G})
\end{aligned}
$$

\section{Theorem 4.4:}

$$
\begin{aligned}
& \text { Let } \mathrm{G} \text { be a } \mathrm{s}_{\mu} \text {-IFG, then } \\
& \qquad \gamma_{\text {ts } \mu \text {-sif }}(\mathrm{G}) \leq \gamma_{\text {ts } \mu \text {-wif }}(\mathrm{G})
\end{aligned}
$$

\section{Proof:}

Let $\mathrm{s}$, $\mathrm{w}$ be a minimal total semi- $\mu$ strong and weak dominating set respectively.

Let $\mathrm{d}_{\mathrm{N}}(\mathrm{u})=\Delta_{\mathrm{N}}(\mathrm{G})$ and $\mathrm{d}_{\mathrm{N}}(\mathrm{v})=\delta_{\mathrm{N}}(\mathrm{G})$. Note that $\mathrm{V}-\mathrm{N}(\mathrm{u})$ is a total semi- $\mu$ strong dominating set and $\mathrm{V}-\mathrm{N}(\mathrm{v})$ is a total semi- $\mu$ weak dominating set of $\mathrm{G}$

$$
\begin{array}{ll} 
& \mathrm{t}_{\text {tsusif }}(G) \leq|\mathrm{V}-\mathrm{N}(\mathrm{u})|_{\text {tsif }} \\
& \mathrm{t}_{\mathrm{ts \mu sif}}(\mathrm{G}) \leq \mathrm{O}(\mathrm{G})-\Delta_{\mathrm{N}}(\mathrm{G}) \\
\& \quad & \mathrm{t}_{\mathrm{ts} \mu \text { wif }}(\mathrm{G}) \leq|\mathrm{V}-\mathrm{N}(\mathrm{v})|_{\text {twif }}
\end{array}
$$




$$
\mathrm{t}_{\mathrm{ts \mu wif}}(\mathrm{G}) \leq \mathrm{O}(\mathrm{G})-\delta_{\mathrm{N}}(\mathrm{G})
$$

we know that

$$
\mathrm{O}(\mathrm{G})-\Delta_{\mathrm{N}}(\mathrm{G}) \leq \mathrm{O}(\mathrm{G})-\delta_{\mathrm{N}}(\mathrm{G})
$$

Using (1) and (2), we get

$$
\mathrm{t}_{\text {tsusif }}(\mathrm{G}) \leq \mathrm{t}_{\mathrm{ts} \mu \text { wif }}(\mathrm{G})
$$

\section{Theorem 4.5:}

For an semi- $\mu$ IFG, $\mathrm{O}(\mathrm{G})-\mathrm{S}(\mathrm{G}) \leq \mathrm{t}_{\text {tspusif }}(\mathrm{G}) \leq \mathrm{O}(\mathrm{G})-\delta_{\mathrm{E}}(\mathrm{G})$ where $\mathrm{O}(\mathrm{G}), \mathrm{S}(\mathrm{G})$ and $\delta_{\mathrm{E}}(\mathrm{G})$ are the order, size and minimum effective incident degree of $\mathrm{G}$ respectively.

\section{Proof:}

Let $\mathrm{D}$ be a dominating set and $\mathrm{t}_{\mathrm{ts} \mu \mathrm{sif}}$ be the minimum total semi- $\mu$ strong domination number in $\mathrm{G}$. Then the scalar cardinality of $\mathrm{V}-\mathrm{D}$ is less than or equal to the scalar cardinality of $\mathrm{V} \mathrm{x} \mathrm{V}$.

$$
\text { Hence } \mathrm{O}(\mathrm{G})-\mathrm{S}(\mathrm{G}) \leq \gamma_{\text {tsp-sif }}(\mathrm{G}) \text {--------(1) }
$$

Now, Let u be the vertex with minimum effective incident degree $\delta_{\mathrm{E}}$

Clearly $\mathrm{V}-\{\mathrm{u}\}$ is a total semi- $\mu$ strong dominating set and hence

$$
\gamma_{\text {ts } \mu \text {-sif }}(\mathrm{G}) \leq \mathrm{O}(\mathrm{G})-\delta_{\mathrm{E}}(\mathrm{G})
$$

From (1) \& (2), we get

$$
\mathrm{O}(\mathrm{G})-\mathrm{S}(\mathrm{G}) \leq \gamma_{\mathrm{ts} \mu \text {-sif }}(\mathrm{G}) \leq \mathrm{O}(\mathrm{G})-\delta_{\mathrm{E}}(\mathrm{G})
$$

It is true for semi- $\mu$ IFG

\section{Theorem 4.6:}

For an semi- $\mu$ IFG, $\mathrm{O}(\mathrm{G})-\mathrm{S}(\mathrm{G}) \leq \gamma_{\text {tsp-sif }}(\mathrm{G}) \leq \mathrm{O}(\mathrm{G})-\Delta_{\mathrm{E}}(\mathrm{G})$ where $\mathrm{O}(\mathrm{G}), \mathrm{S}(\mathrm{G})$ and $\Delta_{\mathrm{E}}(\mathrm{G})$ are the order, size and minimum effective incident degree of $\mathrm{G}$ respectively.

\section{Remark 4.7:}

If all the vertices having the same membership grade, then

(i) $\mathrm{O}(\mathrm{G})-\mathrm{S}(\mathrm{G}) \leq \gamma_{\text {tsp-sif }}(\mathrm{G}) \leq \mathrm{O}(\mathrm{G})-\delta_{\mathrm{E}}(\mathrm{G})$

(ii) $\mathrm{O}(\mathrm{G})-\mathrm{S}(\mathrm{G}) \leq \gamma_{\text {tsu-wif }}(\mathrm{G}) \leq \mathrm{O}(\mathrm{G})-\Delta_{\mathrm{E}}(\mathrm{G})$

\section{Example 5.1:}

\section{Examples}

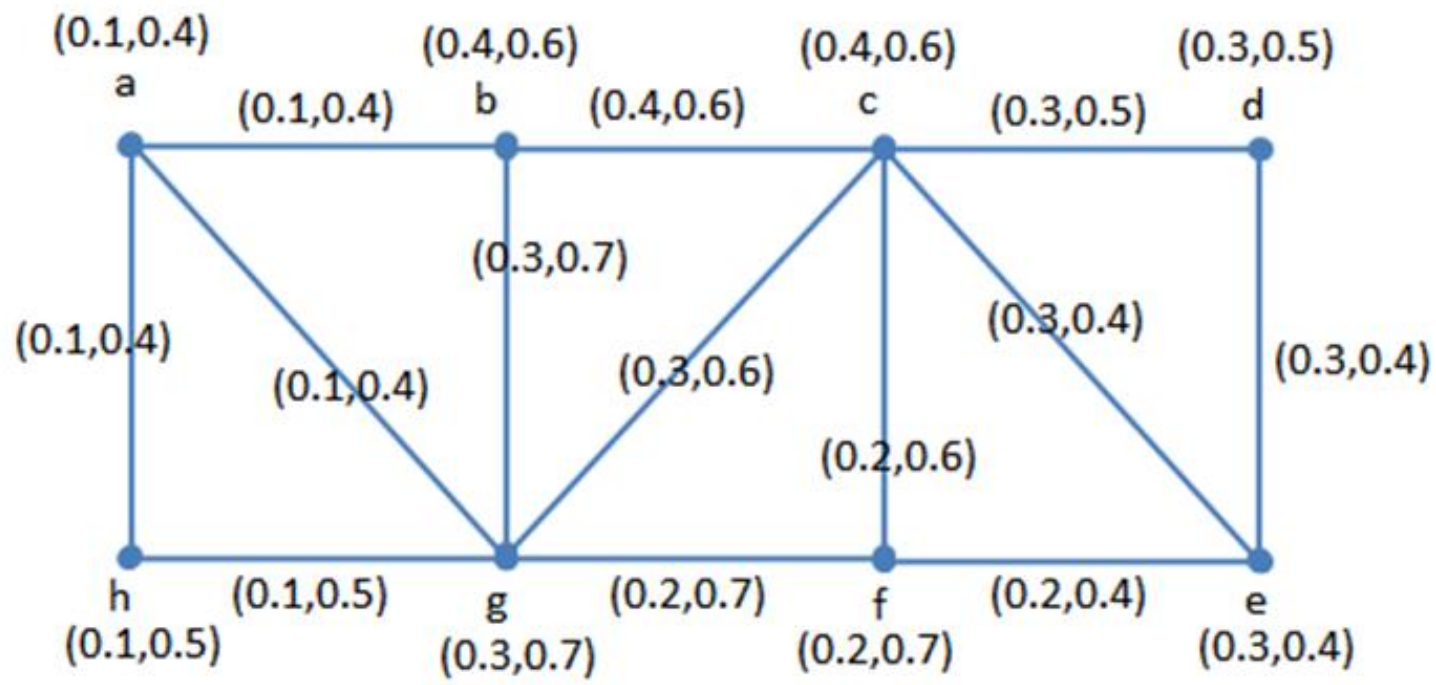




\section{Example 5.2}

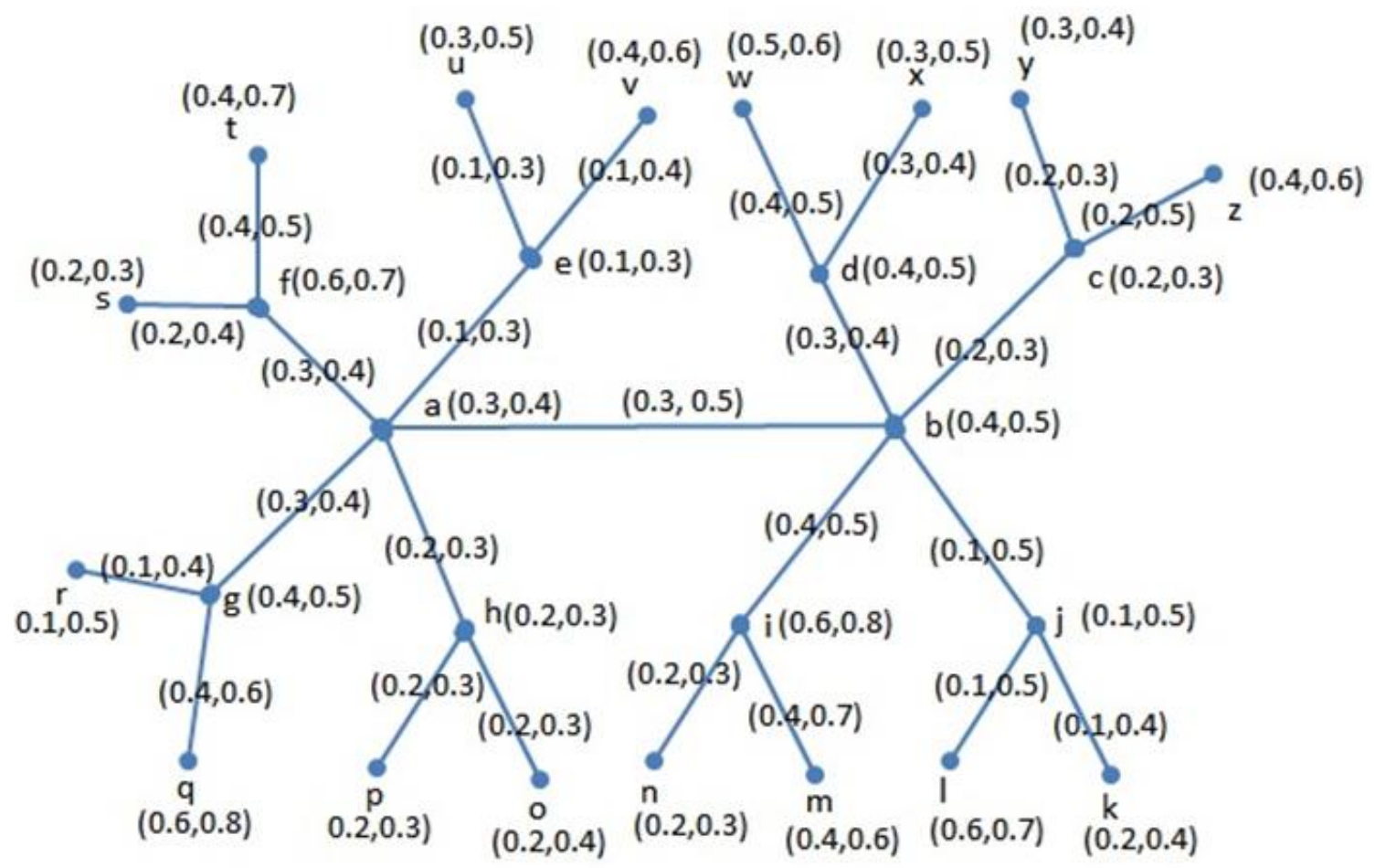

VI. Conclusion

The concept of Total Semi - $\mu$ Strong (Weak) Domination in Intuitionistic Fuzzy Graph is very rich both in theoretical developments and applications. In this paper, we proposed the above concept to prove some theorems and examples. This paper comprises some main definitions which describe the Total Semi - $\mu$ Strong (Weak) Domination in Intuitionistic Fuzzy Graph and also some basic definitions which describe Total Strong (Weak) Domination in Intuitionistic Fuzzy Graph. Considering the theorems described by A. Somasundaram [3] regarding normal fuzzy graph, we have already described some theorems which deal with Total Strong Domination in Fuzzy Graph. This paper enhances that to Total Semi - $\mu$ Strong (Weak) Domination in Intuitionistic Fuzzy Graph. We have given some examples related to Total Semi - $\mu$ Strong (Weak) Domination in Intuitionistic Fuzzy Graph. Still we are having an intention to develop theorems and examples regarding Total Semi - $\gamma$ Strong (Weak) Domination in Intuitionistic Fuzzy Graph in the future.

\section{References}

[1]. A Rosenfeild Fuzzy Graphs; ; in ; L.A. Zadeh, K.S. Fu, M. Shimura(Eds.), Fuzzy sets and Their Applications to Cognitive and Decision processes, Academic Press, New York, 1975, 77 - 95.

[2]. M.G. Karunambigai and R. Parvathi and R. Bhuvaneswari, Constant intuitionistic Fuzzy Graphs, NIFS 17 (2011), 1, 37 - 47.

[3]. A. Somasundaram and S. Somasundaram, Domination in Fuzzy Graphs - I, Pattern Recognition Letters, 19 (1998), 787 - 791.

[4]. Ayyasamy. S and Natarajan. C Strong (weak) domination in Fuzzy graphs, International Journal of Computational and Mathematical Science, 2010

[5]. P.J. Jayalakshmi and C.V.R. Harinarayanan, Independent and Total strong (weak) domination in Fuzzy Graph, International Journal of Computational Engineering Research. / Vol. 04 / Issue, 1, (71 - 74).

[6]. A. Nagoor Gani and S. Shajitha Begum, Degree, Order and Size in Intuitionistic fuzzy Graph, International Journal of Algorithm, Comptuting and Mathematics, (3) 3 (2010).

[7]. Nagoor Gani. A and Basher Ahamed. M, Order and size in Fuzzy Graphs, Bulletin of pure and Applied Science, Vol 22E, 2003; p. $145-148$.

[8]. R. Parvathi and G. Thamizhendhi, Domination in Intuitionistic Fuzzy Graphs, Fourteenth Int. Conf. on IFGs, Sofia 15-16 May 2010 .

[9]. S. Ismail Mohideen and A. Mohamed Ismail, Domination in Fuzzy Graph: A New Approach, International Journal of Computational Science and Mathematics, ISSN 0975-3189, Vol 2, 3 (2010), (101 - 107).

[10]. N. Vinoth Kumar and G. Geetha Ramani, Some Domination Parameters of the Intuitionistic Fuzzy Graphs and its Properties, International Journal of Computational Science and Mathematics, P. $62-65$.

[11]. A. Nagoor Gani and K. Radha, on regular Fuzzy Graphs, Journal of Physical Sciences, (12) (2008), 33 - 140

[12]. A. Nagoor Gani and V.T. Chandrasekaran, Domination in Fuzzy Graphs, Advances in Fuzzy sets and Systems, 1 (1), (2006), 17 26. 